\title{
Textos produzidos pelas crianças ao resolverem situações- problema envolvendo o eixo proporção simples com a classe muitos para muitos
}

\author{
Ana Virginia de Almeida Luna \\ Tania Regina Leite Santos Figueiredo \\ Larissa Borges de Souza Lima
}

\section{Resumo}

Este artigo tem como propósito analisar o processo de produção de textos a partir das estratégias realizadas pelos estudantes para a resolução de situações-problema envolvendo o eixo proporção simples com a classe muitos para muitos e as possíveis aproximações destes textos legítimos. A metodologia utilizada nesta pesquisa envolveu a linguagem de descrição, modelo de investigação sociológica proposto por Bernstein (2000), com o uso da observação e da análise de documentos, envolvendo uma professora, com 30 alunos, com faixa etária entre 10 (dez) a 13 (treze) anos, cursando o $5^{\mathrm{O}}$ ano do Ensino Fundamental dos anos iniciais. Os dados foram produzidos e analisados à luz da teoria bernsteiniana. Como resultado, observamos a relevância da ação do professor em sala de aula, com as atividades de intervenção, e a comunicação na prática pedagógica, para os avanços na diversificação de estratégias, nas aproximações do texto legítimo e na produção de textos legítimos pelos estudantes sobre a multiplicação e a divisão.

Palavras-chave: Anos Iniciais. Multiplicação. Divisão. Formação de professores. Textos legítimos. 


\title{
Texts produced by children when solving problem situations involving the simple proportion axis with the class many to many
}

\author{
Ana Virginia de Almeida Luna \\ Tania Regina Leite Santos Figueiredo \\ Larissa Borges de Souza Lima
}

\begin{abstract}
This article aims to analyze the process of producing texts based on the student's strategies for solving problem situations of simple proportions many for many and the possible approximations of these legitimate texts. The methodology used in this research involved the description language, sociological research model, proposed by Bernstein (2000), using observation and document analysis, involving one teachers and one groups, with 30 (thirty) children, with age range between 10 (ten) years and 13 (thirteen) years old, attending the $5^{\text {th }}$ year of elementary school in the initial years. The data were produced and analyzed in the light of the Bernsteinian theory. As a result, we observed the relevance of teacher action in the classroom, with intervention activities, and communication in pedagogical practice, for advances in the diversification of strategies, in the approximation of the legitimate text and in the production of legitimate texts by students about multiplication and division.
\end{abstract}

Keywords: Early Years. Multiplication. Division. Teacher training. Legitimate texts 


\section{Introdução}

Neste artigo apresentamos o resultado das análises do processo de produção dos textos elaborados por estudantes do $5^{\mathrm{o}}$ ano do Ensino Fundamental que se refere à resolução de situações-problema, do Campo Multiplicativo, envolvendo o eixo Proporção Simples, classe muitos para muitos.

As atividades foram desenvolvidas no contexto do projeto "As Estruturas Multiplicativas e a formação de professores que ensinam Matemática na Bahia” denominado PEM (Núcleo UEFS-Feira), financiado pela Fundação de Amparo à Pesquisa do Estado da Bahia.

Em nosso estudo foram analisadas 24 estratégias desenvolvidas pelos estudantes, de uma das turmas do $5^{\circ}$ ano, participantes da pesquisa, com análises de produções realizadas antes e após a proposta de intervenção elaborada, em conjunto, pela professora da turma e os pesquisadores do projeto PEM.

Ressaltamos que, embora esta pesquisa tenha se desenvolvido no contexto do projeto PEM, que propõe o estudo das Estruturas Multiplicativas, fundamentado na Teoria dos Campos Conceituais de Vergnaud (1983; 1994; 1996), à luz da psicologia cognitiva, em nosso estudo a análise dos textos produzidos pelos estudantes foi fundamentada sob a ótica da abordagem sociológica de Bernstein (1996; 2000; 2003).

Ao analisarmos as estratégias dos estudantes na resolução de diferentes tipos de situações-problema envolvendo a multiplicação e a divisão, observamos o baixo percentual da produção de textos legítimos para resolução das situações-problema do eixo Proporção Simples - muitos para muitos.

Diante disso, o objetivo do nosso trabalho foi analisar o processo de produção de textos a partir das estratégias realizadas pelos estudantes para a resolução de situaçõesproblema envolvendo o eixo proporção simples com a classe muitos para muitos e as possíveis aproximações destes textos legítimos.

Sob as lentes bernsteinianas, o texto é considerado legítimo quando apresenta um significado pertinente ao contexto de uma determinada prática pedagógica (BERNSTEIN, 2003), evidenciando a apropriação do conceito, a aquisição do código, que em nossa análise refere-se à produção do texto adequado à resolução dos problemas multiplicativos de proporção simples - muitos para muitos, antes e após a atividade de intervenção proposta.

Nesta pesquisa, à luz da teoria de Bernstein, o nosso foco de análise não está centrado na verificação de erros e acertos, mas no processo de aproximações pelos quais os alunos vão passando para a produção dos textos legítimos.

Desse modo, neste processo de análise dos textos dos alunos destacamos também a relevância deste trabalho no processo de formação docente, pois ao analisar as produções dos estudantes e com base nelas o docente tem a possibilidade de refletir sobre a sua ação 
pedagógica e pensar de que forma pode intervir, buscando novos caminhos metodológicos para o desenvolvimento da aprendizagem dos estudantes.

\section{Os Processos ee Ensino e Aprendizagem da Multiplicação e Divisão no Contexto Escolar}

Apesar da complexidade que envolve o ensino e a aprendizagem das estruturas multiplicativas, são várias as investigações que revelam que os alunos são capazes de resolver situações-problema envolvendo a multiplicação e a divisão, desde os anos iniciais do ensino fundamental, utilizando uma diversidade de estratégias sem uso dos algoritmos para resolução. Para tanto, são várias as investigações que revelam que os alunos podem e necessitam de resolver uma grande variedade de problemas muito antes da aprendizagem formal das operações.

No entanto, baseando-se no paradigma do exercício (SKOVSMOSE, 2006), a aprendizagem da matemática ainda se desenvolve, na prática escolar, por meio de exercício com intuito de oferecer o conceito matemático pronto, para ser exercitado, ou seja, baseada apenas no pressuposto de que fazendo contas, que em muitas vezes com a mesma ideia, aprende-se matemática. Parece-nos retrógrado esse tipo de visão, mas ela continua a influenciar bastante as escolas e, como consequência, os índices alarmantes e insatisfatórios em testes e exames, aos quais os estudantes são submetidos.

Diante deste fato, não se pode desarticular o estudo das operações com situações lúdicas, atrativas, por meio de projetos que realmente promovam o aprendizado dos estudantes, assim também, o caminho discursivo constituído entre professoras e crianças dos anos iniciais, do ensino fundamental, na produção de discursos matemáticos que envolvam as ideias de multiplicação e divisão, ou seja, só alcançará esse fim se forem exploradas abordagens que priorizem, em sala de aula, a diversificação de estratégias, a comprovação, a argumentação, favorecendo o trabalho coletivo, fortalecendo a autonomia do estudante na produção de suas estratégias para resolução de diferentes tipos de situações envolvendo a multiplicação e a divisão.

Por meio do pressuposto de que os alunos desenvolvem grande parte da sua aprendizagem recorrendo às estratégias próprias de resolução e de que a aprendizagem se dá por meio da investigação, socialização de estratégias para desenvolvimento dos conceitos matemáticos, cabe-nos uma reflexão sobre a aprendizagem da multiplicação e divisão, operações com um grau de complexidade maior inclusive para os professores dos anos iniciais do Ensino Fundamental, que por vezes não insere tal discurso nos primeiros anos da escola por se sentirem inseguros com a produção discursiva das crianças e com a elaboração de sequência didática adequada ao nível de escolaridade delas. 
A proposta apresentada, nos documentos curriculares nacionais, traz o ensino da multiplicação e da divisão desde os primeiros anos do Ensino Fundamental, por meio do uso da calculadora, do cálculo aproximado e do cálculo mental. Dessa forma, Os Parâmetros Curriculares Nacionais - Matemática (BRASIL, 1997, p.55), apontam que o trabalho com as operações deveria se concentrar “[...] na compreensão dos diferentes significados de cada uma delas, nas relações existentes entre elas e no estudo reflexivo do cálculo, contemplando diferentes tipos - exato, aproximado, mental e escrito". Bem como, retoma que a aprendizagem de um repertório básico de cálculos não se dá pela simples memorização de fatos de uma dada operação, mas sim pela realização de um trabalho que envolve a construção, a organização e, como consequência, a memorização compreensiva desses fatos. Por fim, retoma que "muitos dos erros cometidos pelos alunos são provenientes da não disponibilidade desses conhecimentos ou o não reconhecimento de sua presença no cálculo (BRASIL, 1997, p. 120). De acordo ainda com esse documento, isso ocorre, "provavelmente porque não se exploram os registros pessoais dos alunos que são formas intermediárias para se chegar ao registro das técnicas usuais" (BRASIL, 1997, p. 120).

A Matriz de Referência de Matemática para o $5^{\circ}$ ano, adotada no Sistema de Avaliação da Educação Básica (SAEB)/ Prova Brasil (BRASIL, 2008, p.1) aponta que

“...o conhecimento dos números e das operações constitui um saber indispensável no dia a dia dos alunos. Os números estão presentes nos variados campos da sociedade e são usados em cálculos, representações de medidas, localização para a identificação de objetos, acontecimentos e pessoas".

É um dos seus descritores aponta que, para tanto, é importante que os alunos "resolvam problema com números naturais, envolvendo diferentes significados da multiplicação ou divisão: multiplicação comparativa, ideia de proporcionalidade, configuração retangular e combinatória”. (BRASIL, 2008, p.139)

Assim também, o documento curricular mais recente, a Base Nacional Comum Curricular (BNCC), homologada em 20/12/2017 retoma que a "expectativa em relação aos cálculos é de que os alunos resolvam problemas envolvendo diferentes significados das operações, argumentem e justifiquem os procedimentos utilizados para a resolução e avaliem a plausibilidade dos resultados encontrados" (BRASIL, 2017, p. 224). Além disso, de que se espera "que os alunos desenvolvam diferentes estratégias para a obtenção dos resultados, sobretudo por estimativa e cálculo mental, além de algoritmos e uso de calculadoras" (BRASIL, ibid., p. 224). Vale ressaltar que, este documento ainda retoma que, nessa fase, as habilidades matemáticas que os alunos devem desenvolver não podem ficar restritas à aprendizagem dos algoritmos das chamadas "quatro operações”, apesar de sua importância. Portanto, a BNCC 
orienta-se pelo pressuposto de que a aprendizagem em Matemática está intrinsecamente relacionada à compreensão, ou seja, à apreensão de significados dos objetos matemáticos, sem deixar de lado suas aplicações.

Os documentos oficiais ressaltados evidenciam que no currículo dos anos iniciais do fundamental precisam ser trabalhados as noções de multiplicações e divisões. Porém, como ressalta Magina, Santos e Merlini (2014) essas evidências não são levadas em consideração na formulação do currículo de Matemática desenvolvido para os anos iniciais do Ensino Fundamental, sendo que uma das razões diz respeito à própria concepção de currículo que norteia a ação pedagógica do professor, qual seja, a ideia de que aprende a adição, depois a subtração e, em continuidade, a multiplicação e a divisão, como se multiplicar fosse apenas adicionar parcelas repetidas.

Do ponto de vista conceitual, existe uma clara descontinuidade (ruptura) entre essas duas operações. No raciocínio aditivo as situações podem ser analisadas a partir de um único invariante operatório, qual seja, a relação parte e todo - as partes são conhecidas e se procura o todo ou, ainda, o todo e uma das partes são conhecidas e se procura a outra parte. Já nas situações envolvendo o raciocínio multiplicativo o que está em jogo é uma relação fixa (invariante operatório) entre duas quantidades, ou seja, toda situação multiplicativa envolve duas quantidades (de naturezas iguais ou distintas) e uma relação constante entre elas (MAGINA, SANTOS; MERLINI, 2014, p. 517).

Vale ressaltar que para o PEM optou-se por investigar o Campo das Estruturas Multiplicativas ou Campo Conceitual Multiplicativo. O Conjunto das Estruturas Multiplicativas divide-se em dois conjuntos: um conjunto de conceitos e teoremas que permitem analisar as situações cujo tratamento implica em uma ou várias multiplicações e divisões dando origem a variados casos de proporção simples e proporção múltipla (VERGNAUD, 1996).

De acordo com Vergnaud, Gitirana et al. (2014) há uma continuidade entre as operações de adição e multiplicação no que tange a estrutura, para tanto, o mesmo não pode ser dito no que tange aos significados, pois a adição, de modo geral, envolve uma relação ternária e grandezas iguais e a multiplicação envolve, em sua maioria, relações quaternárias. Frente a isso, Vergnaud (2009) apresenta duas grandes categorias para o estudo do Campo Conceitual Multiplicativo, conforme seja a relação envolvida. Cada categoria, em seu interior, possui diversas situações com variados sentidos e significados. Tais categorias são: Medidas (relação quaternária) e Produto de Medidas (relação ternária). A partir dessas categorias, situações de estrutura multiplicativa são classificadas de acordo com eixos, classes e tipos (MAGINA, SANTOS; MERLINI, 2014). Como fica evidenciado na figura 1 abaixo, utilizada como fonte para a formação de professores - um dos contextos da presente pesquisa. 
Figura 1. Esquema do Campo Conceitual Multiplicativo elaborado por Magina, Santos e Merlini (2014)

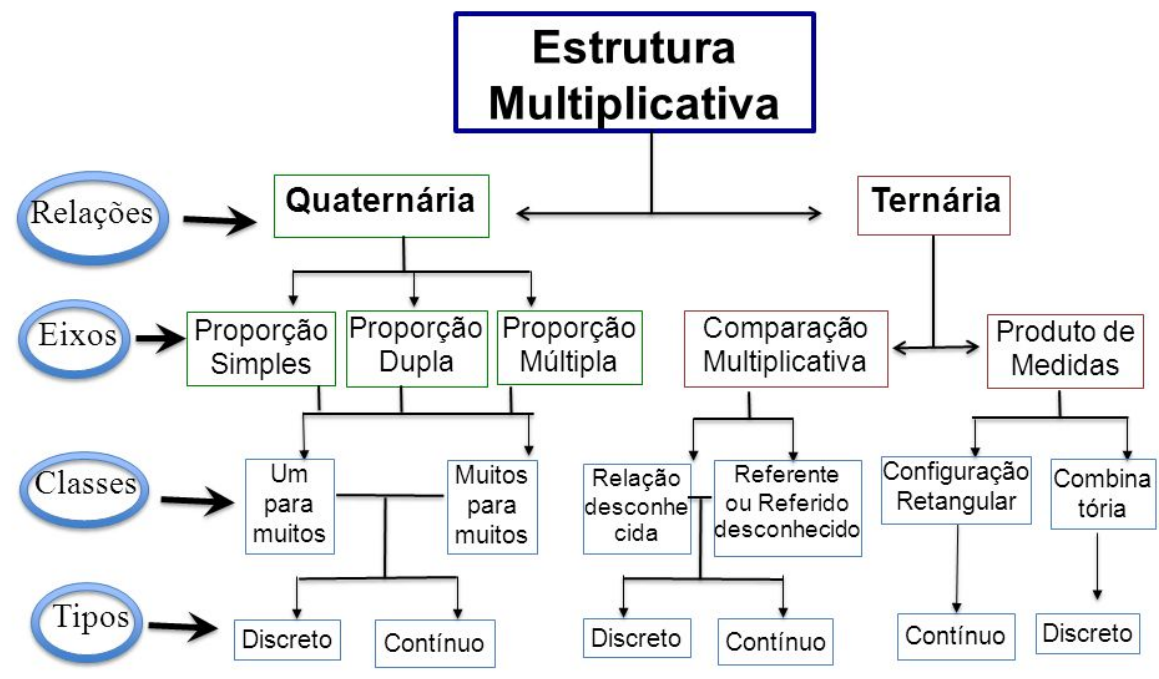

Fonte: SANTOS, 2015

Por exemplo, se considerarmos, na figura 1, a relação quaternária, são apresentados pelos pesquisadores três eixos, a proporção simples, a proporção dupla e a proporção múltipla, os quais estão divididos em duas classes, a saber: a classe de situações de um para muitos e a de muitos para muitos, que podem ser discretas ou contínuas.

Diante do cenário, em âmbito nacional, de baixo índice de desempenho dos estudantes, na área de Matemática, as dificuldades de aprendizagem têm sido objeto de estudo dos educadores matemáticos, que atuam nos anos iniciais do Ensino Fundamental. No artigo produzido por Magina, Santos e Merlini (2014) ficou evidenciado que o desempenho e as estratégias de estudantes dos $3^{\mathrm{o}}$ e $5^{\mathrm{o}}$ anos do Ensino Fundamental, na resolução de duas situações do Campo Conceitual Multiplicativo, classificando os níveis de raciocínio empregados por eles, apontaram para uma evolução limitada da competência dos estudantes ao lidarem com problema multiplicativo, principalmente quando envolve ideia de muitos para muitos, essa evolução cai drasticamente.

Esses dados são reveladores e implica no processo de ensino e aprendizagem de Matemática nos anos iniciais, não favorecendo a produção do texto sobre as ideias de multiplicação e divisão, já que não há, entre os professores, em sua maioria licenciados em Pedagogia, habilitação para a docência da Matemática, distanciando-se dos discursos que envolvem a multiplicação e a divisão. Dessa forma, os poucos documentos orientadores de como inserir, na prática pedagógica, as ideias de multiplicação e divisão, com intuito aos avanços da produção de texto dos estudantes, é um sinal de que esses profissionais precisam de uma formação, fortalecendo a prática pedagógica, pois conforme Brito (2006), 
Seria ingênuo esperar que a formação inicial desse conta de toda a dinâmica do processo ensino e aprendizagem, todavia é coerente buscar, nesse processo, uma sólida formação teórico-prática alicerçada em saberes peculiares ao processo de ensinar/aprender, a fim de formar professores nas concretas situações de ensino, oportunizando, com base nas diferentes leituras do cotidiano da sala de aula, novas apropriações sobre ensinar e aprender (BRITO, 2006, p. 44-45).

Se observarmos o percurso dos professores, de uma forma geral, todos aprenderam que a multiplicação é uma forma rápida de resolver problemas com parcelas iguais. Nessa perspectiva, se em sua formação não forem instigados a descontruir seus paradigmas, que embora corretos sejam muito simplistas, continuarão perpetuando ideais insuficientes do ponto de vista da alfabetização matemática de que o importante é ensinar as quatro operações utilizando-se de apenas uma ideia, não contribuindo para que os estudantes desenvolvam conceitos.

\section{A Leitura das Estratégias da Resolução de Problemas de Multiplicação e Divisão à Luz da Teoria de Bernstein}

Para Bernstein (2000), a prática pedagógica é um contexto social por meio do qual se realiza a produção e reprodução da cultura. Entre tais práticas pedagógicas podem ser incluídas as relações entre engenheiros e mestres de obra, arquiteto e engenheiro, médico e paciente; no contexto escolar, essa prática envolve a relação entre professor e alunos.

Ao focar, de acordo com Bernstein (2003), os princípios de classificação e enquadramento que regulam as práticas pedagógicas, a classificação diz respeito ao o que pode ser dito em um determinado contexto. Podemos relacionar esse termo conforme Bernstein (2003), às regras de reconhecimento do que pode ser dito nesse contexto, e o enquadramento dirá respeito ao como pode ser dito, a forma de produção do texto legítimo, que regula as regras de realização para a produção desse texto. Pelo termo texto, entendemos, aqui, conforme Bernstein (2003, p.175), como "qualquer comunicação falada, escrita, visual, espacial” produzida por alguém. O texto é considerado legítimo quando as suas significações se adequam ao contexto no qual foi produzido. No caso desta pesquisa o texto legítimo de Proporção simples - muitos para muitos.

Na prática pedagógica, as regras de reconhecimento criam os meios que regulam os significados considerados pertinentes em cada contexto. Quanto às regras de realização, elas determinam como relacionar os significados e fazê-los públicos. Essas regras são necessárias para a produção do texto legítimo, pois regulam o modo de unir os significados para a produção de textos legítimos.

Assim, regras de reconhecimento possibilitam que os estudantes sejam capazes de reconhecer conceitos e significados do contexto, ou seja, a especificidade e a compreensão 
desse contexto, no entanto reconhecer o texto não garante que o estudante seja capaz de utilizar estes conceitos de forma adequada e produza o texto legítimo e neste caso dizemos que há uma realização passiva.

No entanto se o estudante reconhece "o que é dito" e sabe "como" utilizar os conceitos, sabe os critérios que irá usar para seleção e produção de seus textos, ou seja, possuem as regras de realização, ele será capaz de produzir o texto legítimo referente aquele contexto e assim fará uma realização ativa.

Desse modo, concluímos com base nos conceitos bernsteinianos que a produção do texto legítimo está associada paralelamente as regras de reconhecimento (reconhecimento "do que é dito”) e as regras de realização (o “como pode ser dito”), de forma que as regras de realização pressupõem as regras de reconhecimento e a produção do texto legítimo é limitada por ambas. Em suma, as regras de reconhecimento e de realização permitem criar o texto adequado ao contexto.

O foco do nosso estudo foi a análise de estratégias para resolução de problemas do tipo Proporção Simples - muitos para muitos, por isso voltou-se para o acompanhamento dos textos produzidos pelos estudantes.

\section{Metodologia}

Como o objetivo do nosso estudo foi analisar o processo de produção de textos a partir das estratégias realizadas pelos estudantes, para a resolução de situações-problema envolvendo o eixo proporção simples com a classe muitos para muitos e as possíveis aproximações destes textos legítimos, foram observados professores que participavam da Formação do Projeto de Estruturas Multiplicativas (PEM), e dentre estes uma sala de aula de uma das professoras, que participava da Formação. O critério de escolha foi ser professor(a) do $5^{\mathrm{o}}$ ano, último ano dos anos iniciais do Ensino Fundamental, estar interessado(a) em participar de todos os encontros da Formação e se apresentar aberto(a) para a realização das atividades em sala de aula. Na Formação do PEM os professores tiveram a oportunidade de aprofundar os estudos sobre a Multiplicação e a Divisão e de planejar atividades para desenvolver em sala de aula e, posteriormente, socializar as experiências realizadas em sala no espaço de formação, de forma reflexiva, com os demais participantes, antes da produção dos planejamentos seguintes.

A professora que participou da pesquisa atuava em uma turma no turno vespertino, de uma escola pública localizada na periferia da cidade de Feira de Santana, interior da Bahia, com 30 alunos, com faixa etária entre 10 (dez) a 13 (treze) anos.

A metodologia utilizada nesta pesquisa envolveu a linguagem de descrição, modelo de investigação sociológica proposto por Bernstein (2000), cujo propósito é favorecer uma relação ISSN 2526-2882

$$
* 119 *
$$


dialética entre os conceitos constituídos por uma teoria e os dados empíricos que são analisados na pesquisa. A linguagem de descrição é constituída por duas linguagens por ele denominadas de interna e externa. A linguagem interna de descrição é caracterizada como uma linguagem conceitual. A linguagem externa de descrição, por sua vez, refere-se à sintaxe empírica mediante a qual a linguagem interna se expressa (BERNSTEIN, 2000). Essa sintaxe empírica expressará o diálogo entre a teoria e os dados da pesquisa.

Em nossa pesquisa o movimento da linguagem externa de descrição para a linguagem interna de descrição (teoria), e vice-versa, ocorreu, como para Bernstein (2000), por meio de um movimento dialético entre essas duas linguagens. Buscamos trabalhar com os dados (linguagem externa de descrição), dialogando com a teoria (linguagem interna de descrição).

Para a produção dos dados foram utilizados, como procedimentos, a observação e a análise documental. Os registros dos dados foram realizados com o gravador de áudio e vídeo e diário de campo. Com as observações, foi possível obtermos as informações necessárias para a descrição do contexto.

\section{Análise dos Dados}

O foco da nossa análise na leitura de estratégias para resolução de problemas do tipo Proporção Simples - muitos para muitos, voltou-se para o acompanhamento dos textos produzidos pelos estudantes antes e após a atividade de intervenção, observando a diversificação na elaboração das estratégias, as aproximações e a produção dos textos legítimos neste processo.

Destacamos que, neste processo de análise, consideramos também as aproximações realizadas pelos estudantes na construção de seus textos, ou seja, os caminhos que os estudantes foram vivenciando, no processo, para compreensão e produção de suas estratégias, já que durante o processo as crianças vão demonstrando avanços, mesmo que não cheguem a produzir textos legítimos.

Conforme foi apresentado na introdução deste artigo, o nosso trabalho de análise está fundamentado na abordagem sociológica bernsteiniana. Desse modo, as categorias de análise foram definidas a partir da leitura dos textos produzidos pelos estudantes com base nos conceitos de Bernstein (1996; 2000; 2003) referentes às regras de reconhecimento e de realização e produção do texto legítimo.

Assim, consideramos importante apresentar sob a ótica bernsteiniana alguns dos conceitos utilizados em nossa análise.

Para o autor a produção do texto depende da forma como ocorre à comunicação e texto é qualquer forma de comunicação que pode ser escrita, falada, visual e ou espacial produzida por uma pessoa, e o texto legítimo é o texto adequado que revela a apropriação do conceito.

ISSN 2526-2882

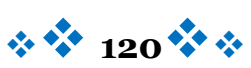


Assim, com base nos conceitos de Bernstein (1996;2000), apresentamos os significados dos termos utilizados em nossa análise:

- Reconhece o texto (regras de reconhecimento) - reconhece o que é dito no texto de uma situação-problema de multiplicação e divisão de Proporção Simples, eixo muitos para muitos, reconhece a sua especificidade e o que é legítimo para a produção do texto.

- Seleciona os significados e produz o texto legítimo (regras de realização) o estudante seleciona os dados adequadamente, com base no que é enunciado na situaçãoproblema, e produz o texto como pode ser dito para resolver a situação-problema, produzindo assim o texto adequado ao contexto, ou seja, o texto legítimo.

A seguir apresentaremos as atividades de intervenção desenvolvida com o eixo proporção simples, classe muitos para muitos e o processo de reconhecimento e seleção dos textos pelos estudantes, o jogo Bingo da Multiplicação e, em seguida, três situações-problema.

\section{O Jogo: Bingo da Multiplicação}

Tomando por base os textos produzidos pelos estudantes na análise inicial na resolução de problemas do eixo Proporção Simples - muitos para muitos, foi planejada, juntamente com a professora da turma, uma atividade inicial de intervenção, no PEM.

No primeiro momento da atividade a professora relembrou aos estudantes o "Bingo da Multiplicação"14, que foi realizado anteriormente com o grupo e os convidou a brincarem outra vez. Para brincar, os estudantes tinham que resolver as operações de multiplicação "cantadas" pela professora e marcar o resultado na cartela. Após a brincadeira, a professora fez alguns questionamentos ao grupo com a finalidade de fomentar discussões.

Inicialmente, ela solicitou a todos os estudantes que contassem a quantidade de números marcados na cartela e, em seguida, socializou oralmente alguns problemas envolvendo o jogo do Bingo. As situações apresentadas inicialmente envolveram o eixo Proporção Simples - um para muitos e ao responder oralmente, estas questões, os alunos não demonstraram dificuldades.

- Considerando que cada número que você marcou na cartela vale 2 pontos, quantos pontos você conseguiu fazer no total?

\footnotetext{
${ }^{14} \mathrm{O}$ jogo "Bingo da Multiplicação" foi confeccionado pela professora do grupo, sendo composto por cartelas com diversos resultados (produtos); fichas com as operações de multiplicação e uma caixa para colocar as fichas que seriam sorteadas. ISSN 2526-2882 
Com base na quantidade de números marcados os estudantes foram dando as respostas.

- Como todos viram Bruno foi o primeiro a marcar todos os números da sua cartela e foi o ganhador do brinde. Quantos números têm em cada cartela? Se cada número marcado valer 4 pontos, qual o total de pontos de Bruno?

Após a socialização das respostas, pelos estudantes, a professora socializou que as situações apresentadas envolviam a relação um para muitos, explicando que cada número marcado estava relacionado a mais de um ponto, ou seja, estava relacionada a muitos.

Dando continuidade às discussões em grupo, a professora fez questionamentos referentes à vivência do Bingo com situações que envolviam o eixo Proporção Simples - muitos para muitos.

-Agora, vamos pensar que 2 números marcados na cartela valem 2 pontos. Se Renata marcou 6 números em sua cartela, quantos pontos Renata fez no total?

- Agora, vamos pensar que 2 números marcados na cartela valem três pontos. Que situação-problema podemos criar com estes dados?

Diante da proposta da professora, os alunos construíram coletivamente a situaçãoproblema que vemos na Figura 2, registrada na lousa.

- Se 2 números marcados valem 3 pontos e na cartela temos nove números, quantos pontos Amanda fez?

Figura 2. Situação-problema elaborada coletivamente pela professora e estudantes

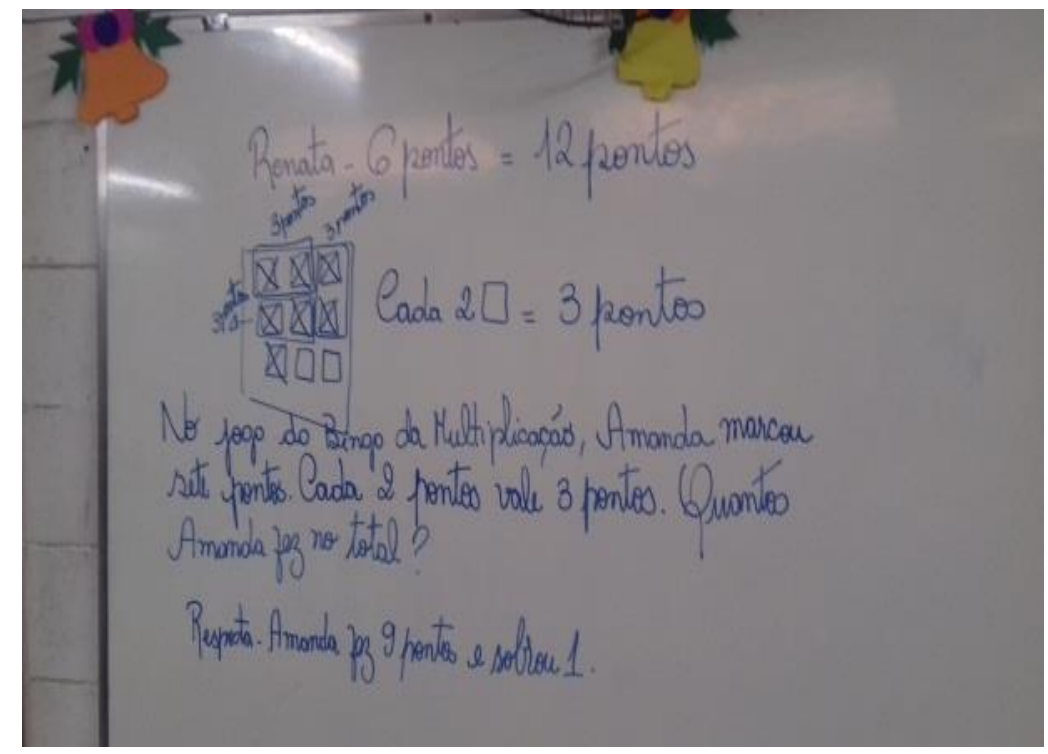

Fonte: As autoras

Desse modo, dando continuidade, a professora foi fazendo novas intervenções e alguns alunos se dispuseram a registrar no quadro suas estratégias para resolução das diferentes ISSN 2526-2882

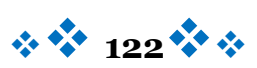


situações que iam sendo propostas oralmente pela docente, conforme podemos ver na Figura 3 .

Figura 3. Alunos socializando suas estratégias de resolução para as situações propostas na lousa
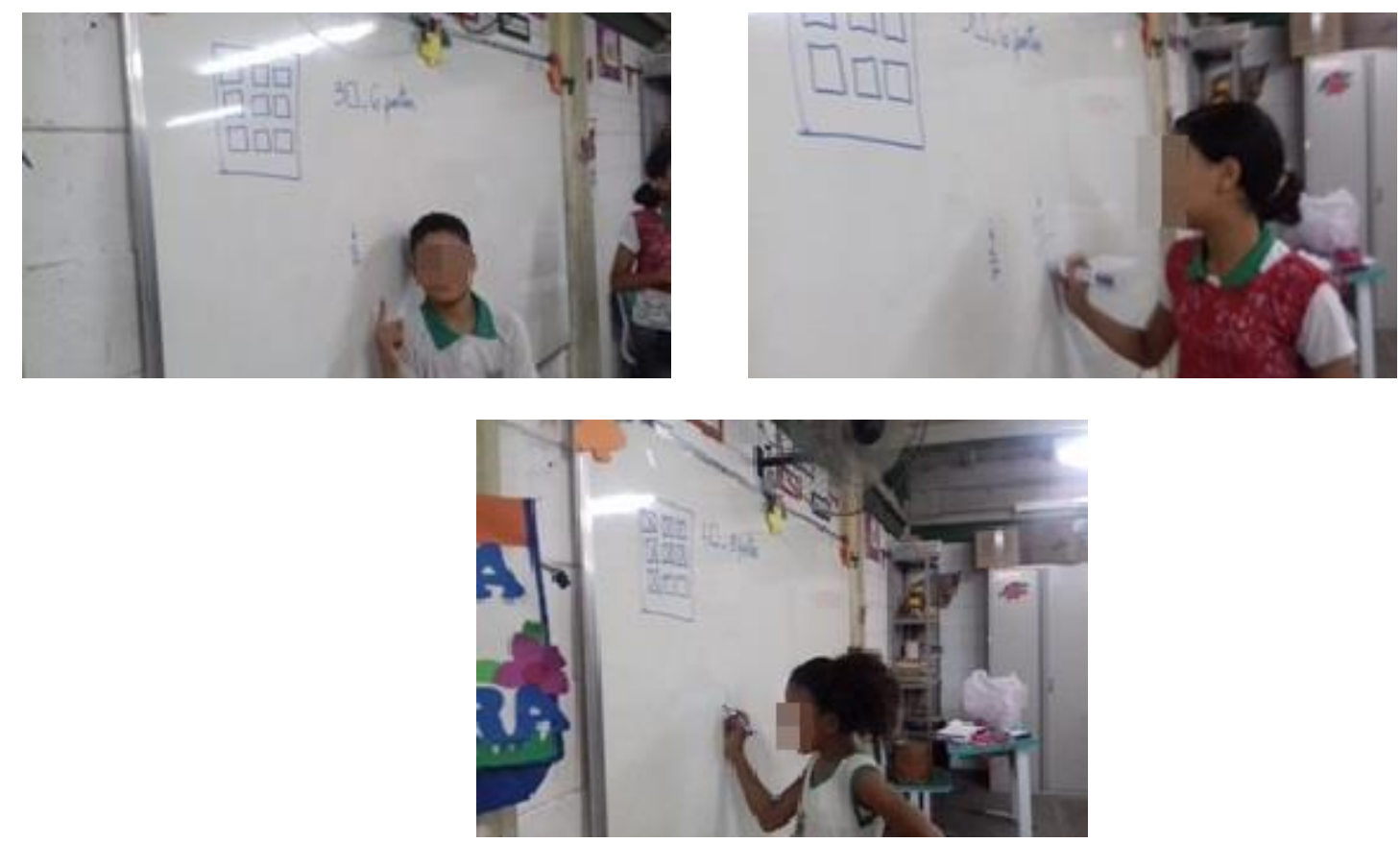

Fonte: As autoras

Ao final das intervenções, a professora chamou atenção para o fato de que nas situações apresentadas a relação foi de mais de um número marcado, para mais de um ponto, ou seja, a relação muitos para muitos.

Observamos que o grupo se envolveu na discussão, muitos quiseram participar e que nas estratégias apresentadas na lousa os estudantes utilizavam a adição de parcelas iguais e o algoritmo da multiplicação para resolver as situações propostas.

Após este primeiro momento de intervenções, de discussões em grupo e socialização das estratégias utilizadas, a professora propôs a realização da atividade escrita com as três questões da atividade de retomada que envolvem o eixo Proporção Simples, correspondência muitos para muitos.

\section{Três Situações-Problema Propostas}

Nesta seção, apresentaremos a análise dos textos produzidos pelos estudantes ao resolverem as três situações-problema do eixo Proporção Simples, correspondência muitos para muitos, apresentados no Quadro 1. 
Quadro 1. Situações-problema do eixo Proporção Simples (muitos para muitos)

\begin{tabular}{|l|l|l|}
\hline Problema Q3 & Problema Q6 & Problema Q12 \\
\hline $\begin{array}{l}\text { Para fazer uma fantasia são } \\
\text { necessários 5m de tecido. Ana } \\
\text { tem 35m de tecido. Quantas } \\
\text { fantasias ela pode fazer? }\end{array}$ & $\begin{array}{l}\text { e pagou 15 reais. Se ele } \\
\text { comprasse 3 caixas de suco }\end{array}$ & $\begin{array}{l}\text { Em uma gincana na Escola } \\
\text { qa quada a voltas correndo } \\
\text { na quadra o aluno marca 4 } \\
\text { pontos. Alex deu 15 voltas } \\
\text { correndo na quadra. Quantos } \\
\text { pontos ele marcou? }\end{array}$ \\
\hline
\end{tabular}

Fonte: Dados da pesquisa - Projeto PEM

Analisaremos o processo de produção dos textos dos estudantes, os processos discursivos desenvolvidos no percurso antes e após a realização da atividade de intervenção, em que buscamos observar as aproximações, ao longo do processo, para chegar a produção do texto legítimo ou os avanços ocorridos no processo, mesmo que alguns estudantes não tenham chegado a produzir textos legítimos.

No grupo observado tinha trinta estudantes matriculados, mas estiveram presentes para a realização da atividade apenas 24 (vinte e quatro) estudantes. As situações-problema realizadas pelos alunos foram as mesmas que eles resolveram na atividade diagnóstica do PEM. No quadro 2, a seguir, apresentamos uma síntese que fizemos dos resultados considerando as três situações-problema e a produção dos textos legítimos e não legítimos no processo de resolução dos problemas pelos estudantes, antes da intervenção, e quantidades de produção após a intervenção na prática pedagógica.

Quadro 2. Comparativo das produções textuais por questão antes e após a atividade de intervenção

\begin{tabular}{|c|c|c|c|c|c|}
\hline \multicolumn{3}{|c|}{$\begin{array}{c}\text { Textos produzidos } \\
\text { (antes da intervenção) }\end{array}$} & \multicolumn{3}{c|}{$\begin{array}{c}\text { Textos produzidos } \\
\text { (após a intervenção) }\end{array}$} \\
\hline Questões & $\begin{array}{c}\text { Textos } \\
\text { legítimo } \\
\text { s }\end{array}$ & $\begin{array}{c}\text { Textos } \\
\text { não legítimos }\end{array}$ & $\begin{array}{c}\text { Categoria 1 } \\
\text { Textos } \\
\text { não legítimos }\end{array}$ & $\begin{array}{c}\text { Categoria 2 } \\
\text { Aproximações }\end{array}$ & $\begin{array}{c}\text { Categoria } 3 \\
\text { Textos } \\
\text { Legítimos }\end{array}$ \\
\hline Q3 & 05 & 19 & 05 & 04 & 15 \\
\hline Q6 & 08 & 16 & 08 & 04 & 12 \\
\hline Q12 & 10 & 14 & 03 & 03 & 18 \\
\hline
\end{tabular}

Fonte: As autoras

Diante do quadro 2 temos a categoria 1, que se refere aos textos produzidos em que os estudantes não reconhecem e não selecionam significados do contexto da situação-problema para a produção dos textos legítimos. Quanto a categoria 2, diz respeito aos textos produzidos em processo de passagem da realização passiva para realização ativa e aproximações do texto legítimo após atividades de intervenção. E, por fim, a categoria 3, que se refere à produção de textos legítimos.

Na subseção a seguir analisaremos algumas situações-problema considerando essas categorias. 
Análise Das Situações-Problema Antes E Depois Da Atividade De Intervenção

- Situação-problema Q3

Nesta situação temos a proporção 3 (três) fantasias - (grandeza) para 5m (cinco metros) - (medida), considerando um todo de 35m. A questão busca saber quantas fantasias é possível fazer. Assim temos a relação quaternária:

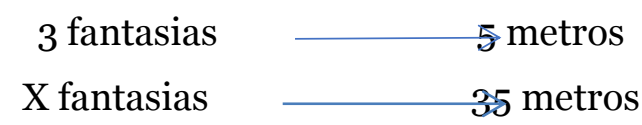

Nesta situação, conforme o planejamento, a professora poderia fazer os seguintes questionamentos para a resolução da situação, a saber: Quantas vezes $5 \mathrm{~m}$ (cinco metros) cabem em 35 metros? Quantas vezes temos $5 \mathrm{~m}$ metros em 35 metros?

Assim, a partir destes questionamentos os estudantes poderiam chegar a solução do problema, pois se em cada 35m (trinta e cinco metros) de tecido em tenho 7 (sete) vezes $5 \mathrm{~m}$ (cinco metros), e que com esta quantidade de tecido é possível fazer 3(três) fantasias, seria possível fazer então 21 fantasias com 35m (trinta e cinco metros) de tecido.
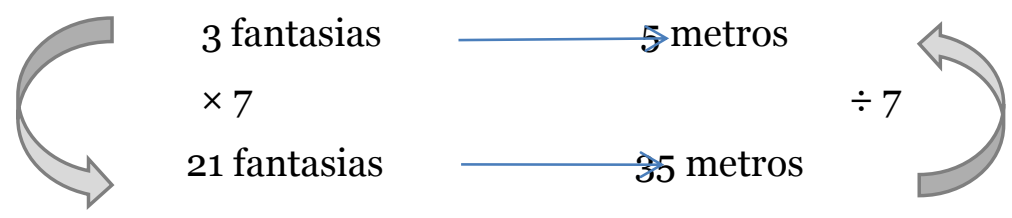

Na resolução desta situação-problema antes da atividade de intervenção, de 24 (vinte e quatro) textos analisados, 5 (cinco) produções foram de textos legítimos e 19 (dezenove) produções de textos não-legítimos. Vejamos algumas produções dos estudantes na resolução desta situação-problema antes da atividade de intervenção nas Figuras 4, 5 e 6.

Figura 4. Texto produzido pelo estudante C23

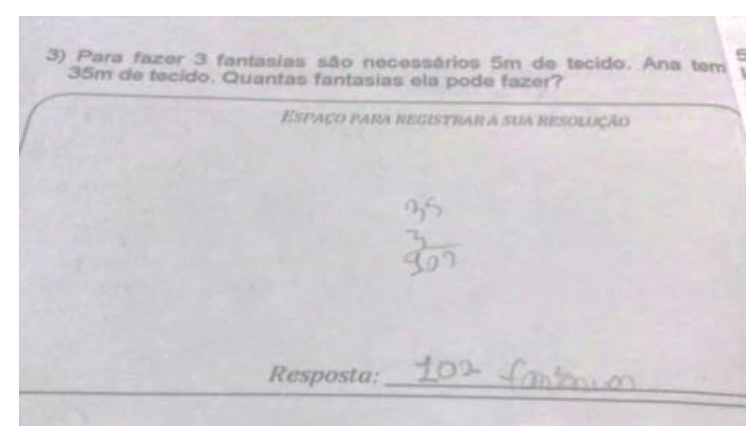

Fonte: Protocolo PEM C23, 2017
Figura 5. Texto produzido pelo estudante $\mathrm{C} 15$

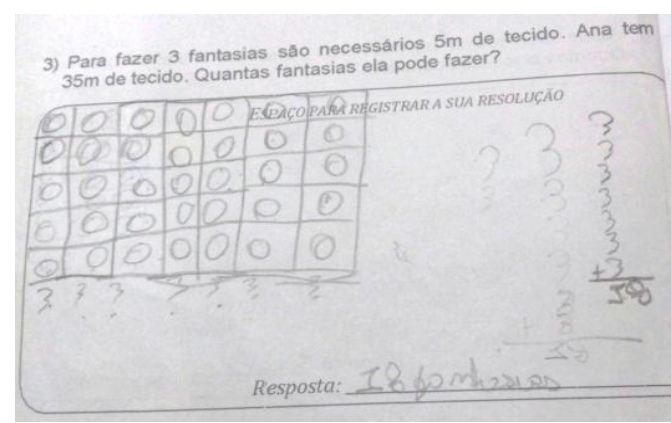

Fonte: Protocolo PEM C15, 2017 
Figura 6. Texto produzido pelo estudante $\mathrm{C} 16$

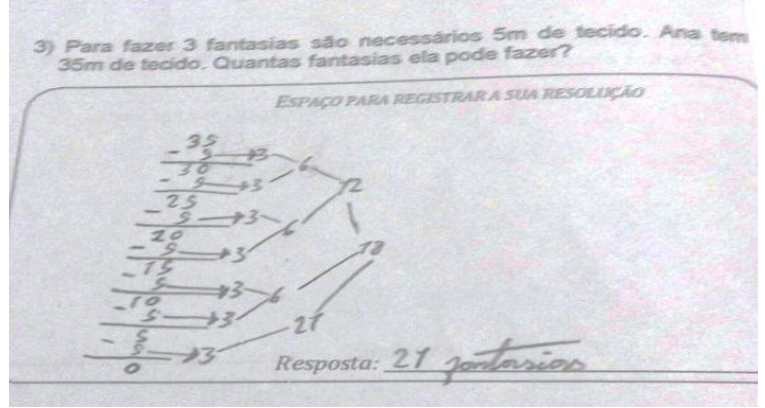

Fonte: Protocolo PEM C16, 2017

Na figura 4, analisamos que o estudante C23 não reconhece o texto e consequentemente não seleciona os critérios adequados para a resolução do problema e, neste caso, não possui as regras de reconhecimento, as regras de realização e, portanto, não produz o texto legítimo.

Ao analisar a estratégia do estudante C15 (figura 5) observamos que o estudante reconhece o texto, seleciona os significados referentes ao contexto da situação-problema, no entanto não produz o texto legítimo. Desse modo, o estudante $\mathrm{C}_{15}$, possui as regras de reconhecimento e realização, porém não produz o texto legítimo, ou seja, segundo os conceitos bernsteinianos desenvolve apenas uma realização passiva.

Figura 7 Descrição do textos produzidos pelo estudante C15

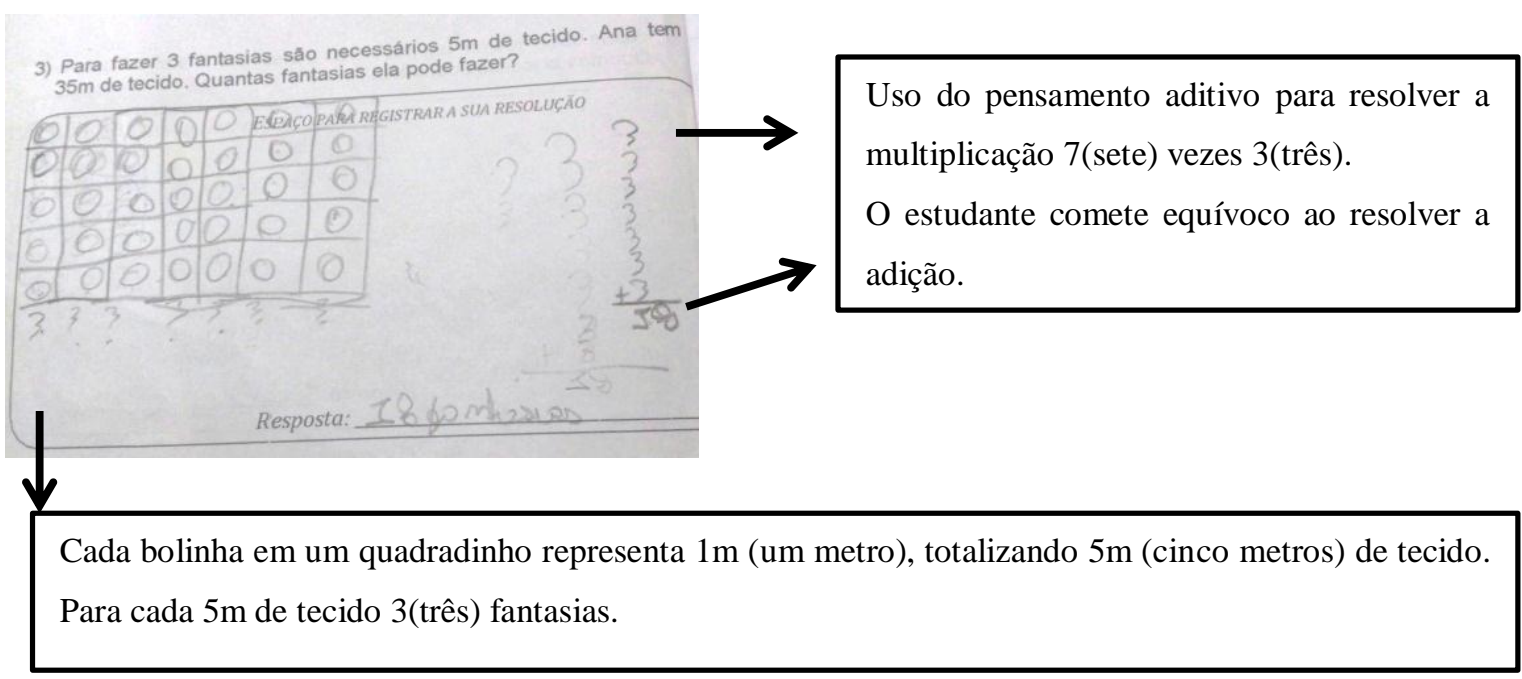

Fonte: Protocolo PEM C15, 2017

Como pode ser visto na figura 7, a realização pode ser considerada como passiva, pois ele apresenta o texto para a resolução da situação-problema, organiza as sete parcelas da adição com o três, mas o total da operação não está adequado, ou seja, o texto não é legítimo. No que se refere ao outro texto, o estudante também representa de forma adequada, mas não controla

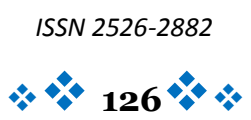


o resultado. Estava previsto um espaço de interação entre os estudantes para discutirem as suas resoluções, a fim de que pudessem retomar as suas produções. Após a discussão, o estudante $\mathrm{C} 15$ retomou a sua resolução (figura 8).

Figura 8. Texto produzido por C15 depois da intervenção

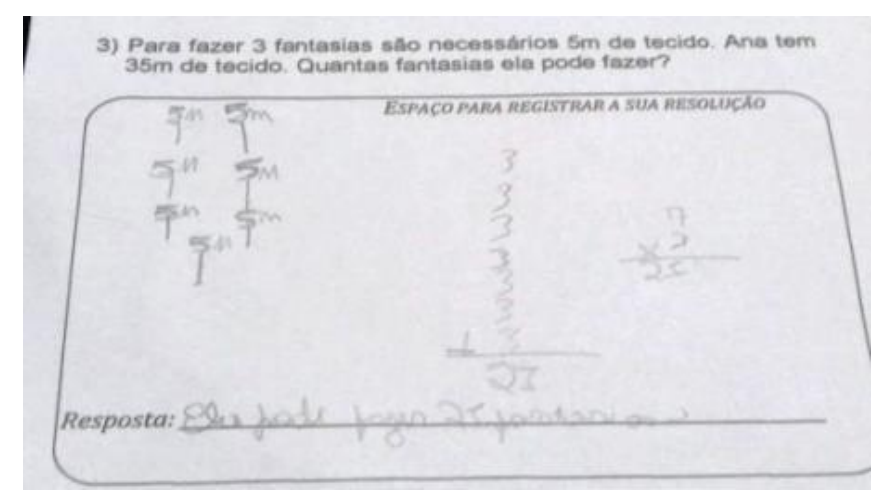

Fonte: Protocolo PEM C15, 2017

Na figura 8, C15 produz um texto legítimo. Pela diversidade de estratégias que ele apresentou, podemos inferir que ele está se aproximando de uma realização ativa.

Quanto ao estudante C16, figura 6, observamos que ele reconhece o texto, seleciona significados e produz o texto legítimo, comunicando por meio do seu texto as regras de reconhecimento e realização, desenvolvendo uma realização ativa e produzindo um texto legítimo (figura 9).

Figura 9 Descrição do textos produzidos pelo estudante C16

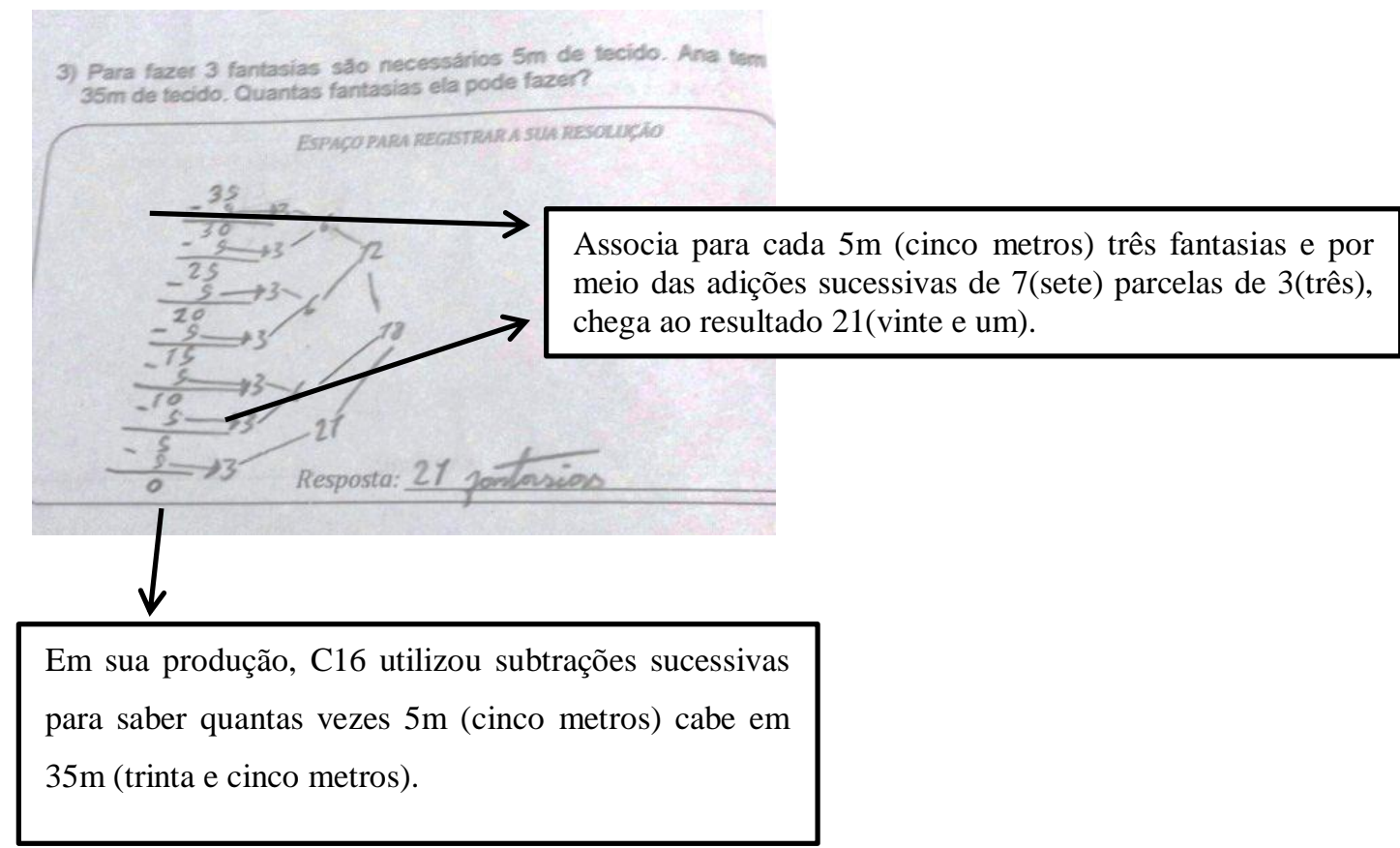

Fonte: Protocolo PEM C16, 2017 
- $\quad$ Situação-problema Q6

Ao analisar os textos produzidos referentes a esta situação-problema Q6, no total, 8(oito) estudantes produziram textos legítimos e 16 (dezesseis) estudantes produziram textos nãolegítimos.

Para resolver esta situação-problema, ao planejar a atividade inferimos que, para encontrar o resultado, um dos caminhos que os estudantes poderiam percorrer era fazer a relação entre as grandezas 9 (nove) e 3 (três), associando que se 9 (nove) caixas de suco custam $\mathrm{R} \$ 15,00$ (quinze reais) no total e que 9 (nove) é múltiplo de 3 (três), então, para cada 3 (três) caixas, Caio pagou $\mathrm{R} \$ 5, \mathrm{Oo}$ (cinco reais).

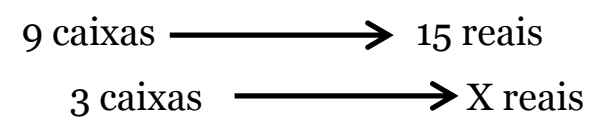

Desse modo, 15(quinze) dividido por 3(três) é igual a cinco. Assim, para cada 3(três) caixas de suco o valor pago foi de $\mathrm{R} \$$ 9,oo (nove reais).

Em séries mais avançadas do Ensino Fundamental 2, para resolver esta situação, os estudantes usariam a regra de três simples. No entanto, o nosso propósito, na formação do PEM, foi orientar os professores a trabalhar com seus alunos diferentes tipos de situações multiplicativas, desmitificando a concepção que a multiplicação e a divisão não podem ser trabalhadas nos primeiros anos da escolaridade e que situações deste tipo não podem ser realizadas com alunos do $1^{\mathrm{o}}$ ao $5^{\mathrm{o}}$ ano do Ensino Fundamental.

No entanto, o que observamos em nossa análise é que mesmo sem ter estudado a regra de três simples, conforme estabelecido nos currículos escolares tomando por base o repertório dos conteúdos que são abordados, os estudantes com uso de diferentes tipos de estratégias já são capazes de resolver este tipo de situação no $5^{\mathrm{o}}$ ano dos anos iniciais no do Ensino Fundamental, conforme podemos ver na figura 10.

Figura 10. Texto produzido pelo estudante $\mathrm{C}_{3}$

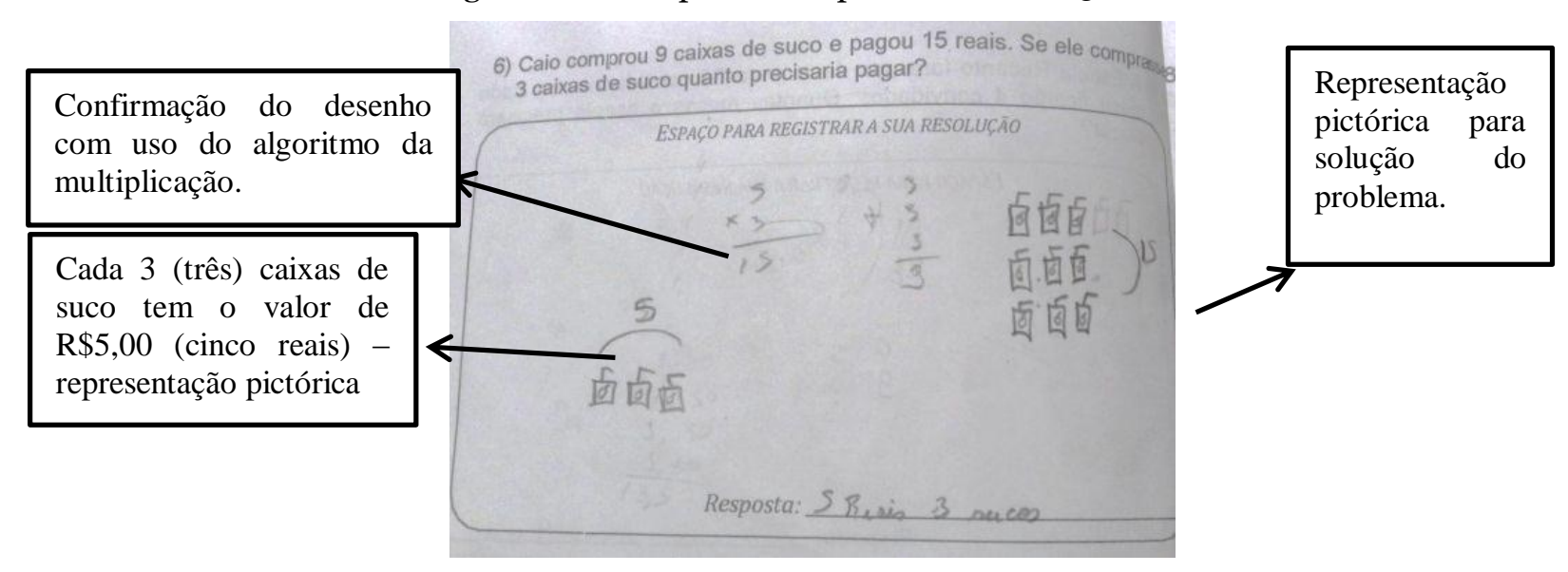

Fonte: Protocolo PEM C3, 2017

ISSN 2526-2882 
É possível observar que o estudante $\mathrm{C}_{3}$ utilizou em seu texto, como estratégias de resolução, representações pictóricas e paralelamente os algoritmos. Os desenhos desenvolvidos pelo estudante nos permitiu, em nossa análise, acompanhar o percurso feito para encontrar a solução do problema. Vale ressaltar que, observamos em muitas produções este processo de elaboração, o que nos fez concluir que neste momento os alunos estavam menos algoritimizados e buscavam meios de resolução requintados e elaborados, passo a passo, para desenvolver suas estratégias.

No caso do estudante $\mathrm{C}_{3}$, analisamos que houve a produção do texto legítimo, pois o aluno possui as regras de reconhecimento e realização, uitlizando-se de critérios legítimos para produzir o seu texto.

\section{- $\quad$ Situação-problema Q12}

A situação-problema Q12 apresentou, do total de textos analisados, o maior índice de produção de textos legítimos antes da atividade de intervenção, se comparada as outras situações analisadas, totalizando 10 (dez) produções de textos legítimos e 14 (quatorze) produções de textos não-legítimos.

É importante salientar que, analisamos a realização de diferentes atividades prévias envolvendo jogos durante o processo de formação do projeto PEM, bem como o desenvolvimento destas atividades em sala, por parte da professora do grupo participante deste estudo, foi um dos fatores que favoreceu estes resultados.

Nesta situação, ao planejar a realização da atividade, pensamos que um dos caminhos que poderia ser percorrido pelos estudantes seria pensar: Quantas 3 (três) voltas cabem em 15 (quinze) voltas?

Nesta situação temos a relação direta entre as grandezas, número de voltas e quantidade de pontos.

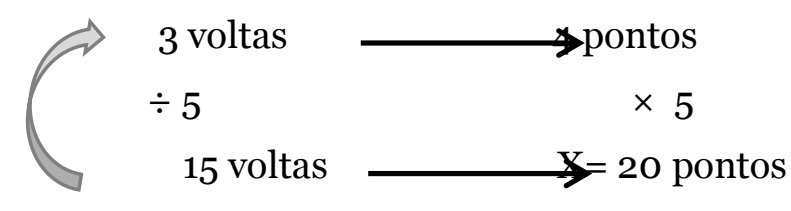


Vejamos as estratégias apresentadas nas Figuras 11 e 12.

Figura 11. Texto produzido pelo estudante $\mathrm{C} 1$

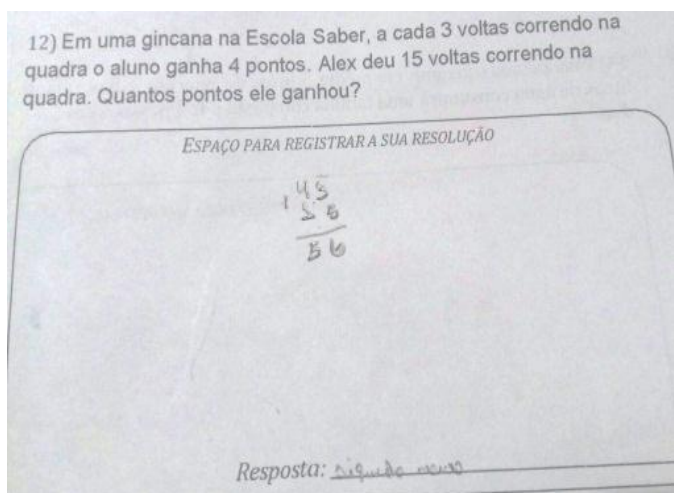

Fonte: Protocolo PEM C1, 2017
Figura 12. Texto produzido pelo estudante $\mathrm{C} 13$

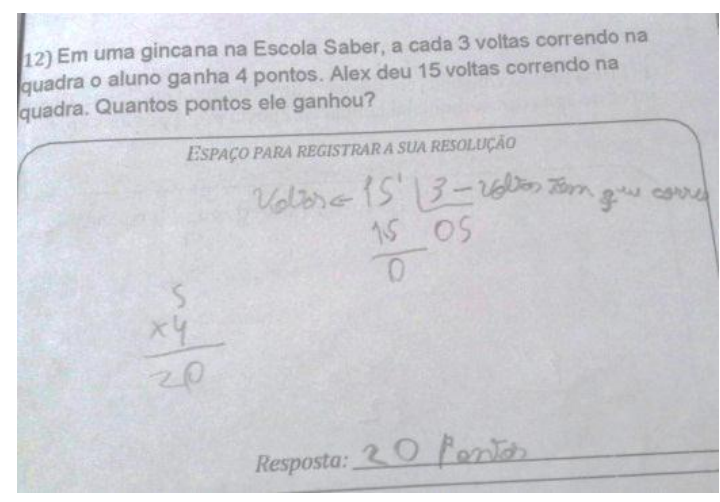

Fonte: Protocolo PEM C13, 2017

$\mathrm{Na}$ análise da estratégia do estudante $\mathrm{C}$, figura 11,observamos que o mesmo não possui as regras de reconhecimento do texto referente ao problema multiplicativo do eixo Proporção Simples, correspendência muitos para muitos, ao utilizar em seu texto o algoritmo da adição para resolver a situação e não seleciona os significados com base no contexto proposto. Desse modo, analisamos que o estudante não possui as regras de reconhecimento e realização.

Já o aluno $\mathrm{C} 13$, conforme podemos ver na figura 12, produziu o texto legítimo, pois reconhece o contexto e estabele critérios de seleção para produção do seu texto, ou seja, o como pode ser dito, desenvolvendo uma realização ativa.

\section{Considerações Finais}

Neste artigo tivemos a oportunidade de analisar o processo de produção de textos a partir das estratégias realizadas pelos estudantes, para a resolução de situações-problema envolvendo o eixo proporção simples, com a classe muitos para muitos, e as possíveis aproximações destes textos legítimos.

A partir desta análise, foi possível observarmos a relevância da ação do professor em sala de aula, com as atividades de intervenção, tendo em vista os avanços dos estudantes na diversificação de estratégias, nas aproximações do texto legítimo e na produção de textos legítimos sobre a multiplicação e a divisão.

Com a pesquisa, outra implicação da pesquisa foi a multiplicidade nas formas de comunicação que foram estabelecidas na prática pedagógica, tendo em vista que quando os estudantes socializavam as suas produções comparavam com as dos outros alunos e tinham a oportunidade de retomar a sua produção, ainda que produzindo outros novos textos, diferentes dos produzidos pelos colegas, se inspiravam em estratégias apresentadas em momentos de socialização. 
Dessa forma, os diferentes tipos de situações-problema envolvendo a multiplicação e divisão e a socialização dos textos produzidos pelos estudantes, por meio de atividades lúdicas e interativas, potencializou os estudantes para produzirem textos legítimos acerca da multiplicação e divisão. Consequentemente, favorecendo as aprendizagens dos estudantes, bem como, a produção de conceitos e futuras teorizações.

\section{Referências}

BERNSTEIN, B. A estruturação do discurso pedagógico: classe, códigos e controle. Vozes: Petrópolis, 1996.

BERNSTEIN, B. Pedagogy, symbolic control and identity: theory research Critique. Revised Edition. London: Taylor and Francis, 2000.

BERNSTEIN, B. Class, codes and control: The structuring of pedagogic discourse. Londres: Routledge, 2003.

BRASIL, Ministério da Educação. Base Nacional Comum Curricular - BNCC. Brasília, DF, 2017.

. Ministério da Educação. PDE: Plano de Desenvolvimento da Educação. Prova Brasil: ensino fundamental: matrizes de referência, tópicos e descritores. Brasília: MEC, SEB; Inep, 2008. 193 p.: il.

. Secretaria da Educação Fundamental. Parâmetros Curriculares Nacionais Matemática. v.3. Rio de Janeiro: DP\&A, 1997.

BRITO, A. E. Formar Professores: rediscutindo o trabalho e os saberes docentes. In: MENDES SOBRINHO, J. A.C. Formação de Professores: Olhares contemporâneos. Belo Horizonte: Autêntica, 2006.

GITIRANA, V.; CAMPOS, T.; MAGINA, S.; SPINILLO, A. Repensando a Multiplicação e a Divisão: contribuições da Teoria dos Campos Conceituais. São Paulo, Ed. PROEM Ltda, 2014.

MAGINA, S.; CAMPOS, T.; GITIRANA, V; NUNES, T. Repensando Adição e Subtração: contribuições da Teoria dos Campos Conceituais. São Paulo, Ed. PROEM Ltda, 2001. MAGINA, S. SANTOS, A.; MERLINI, V. Comparação multiplicativa: a força que a expressão exerce na escolha das estratégias de resolução dos estudantes. In: CIAEM, XIII, 2011. Recife. Anais... Recife, 2011, p. 1-13.

. O raciocínio de estudantes do Ensino Fundamental na resolução das estruturas multiplicativas. Ciência \& Educação (Bauru), v.20, n. 2, p. 517-533. 2014.

\section{SANTOS, A. Formação de professores e as estruturas multiplicativas:}

reflexões teóricas e práticas. 1. Ed. Curitiba: Appris, 2015.

ISSN 2526-2882 
SKOVSMOSE, O. Desafios da reflexão em educação matemática crítica. $1^{\text {a }}$. São Paulo: Papirus, 2008.

VERGNAUD, G. Entrevista publicada na Revista GEEMPA, n. 11, p. 15-23, setembro. Entrevista concedida à Candy Marques Laurendon, 2015.

.. A trama dos campos conceituais na construção dos conhecimentos. Revista do GEMPA, nº 4, p. 9-19, 1996.

A teoria dos campos conceituais. In: BRUN, Jean (dir.). Didática das matemáticas. Trad. Maria José Figueiredo. Lisboa: INSTITUTO PIAGET, p. 155-19, 1996.

\section{Biografia Resumida}

Ana Virginia de Almeida Luna - Licenciada em Pedagogia, Universidade Estadual de Feira de Santana- UEFS (1993) e Licenciatura em Matemática, Faculdade de Tecnologia e Ciências (2008). Especialista em Alfabetização, AVANTE (1997) e em Educação Matemática, Universidade Católica de Salvador (2008). Mestre em Educação Especial UEFS/ Centro de Referência Latino Americano de Cuba (2002), Doutora em Ensino, Filosofia e História das Ciências, com ênfase em Educação Matemática, UEFS/ Universidade Federal da Bahia (2012). Professora Adjunta do Departamento de Ciências Exatas e do Programa de Pós-graduação em Educação (PPGE), UEFS (Feira de Santana-Ba). Diretora Pedagógica do Ensino Fundamental da Escola Despertar ( Feira de Santana-Ba). Coordenadora do Grupo de Pesquisa "Núcleo de Pesquisa em Educação Matemática de Feira de Santana” (NEEMFS/ SBEMBA/ UEFS).

Link do lattes: http://lattes.cnpq.br/1714028887047690

e-mail: avalmeidaluna@hotmail

Tania Regina Leite Santos Figueiredo - Licenciada em Pedagogia pela Universidade Estadual de Feira de SantanaUEFS (1996). Especialista em: Alfabetização pela UEFS (2001), Gestão Escolar pela Unyahna/BA (2012) e Coordenação ISSN 2526-2882 
Pedagógica pela UFBA (2014). Mestranda do Programa de Pósgraduação em Educação (PPGE) da Universidade Estadual de Feira de Santana(UEFS). Coordenadora Pedagógica, lotada no Colégio da Polícia Militar em Alagoinhas, pela Secretária de Educação do Governo da Bahia com experiência na orientação de professores do Ensino Fundamental II e Ensino Médio. Integrante do Núcleo de Estudos e Pesquisas de Educação matemática de Feira de Santana (NEEMFS/UEFS).

Link do lattes: http://lattes.cnpq.br/9229063314817944

e-mail: esther.tania@gmail.com

Larissa Borges de Souza Lima - Especialista em Gramática e Texto (UNIFACS). Graduanda em Matemática - Universidade Norte do Paraná. Coordenadora Pedagógica do Ensino Fundamental da Escola Despertar ( Feira de Santana-Ba). Integrante do Núcleo de Estudos e Pesquisas de Educação Matemática de Feira de Santana (NEEMFS/UEFS).

e-mail: limaborgeslarissa@gmail.com

Link do lattes: http://lattes.cnpq.br/4531643459297008 